BMC

Evolutionary Biology

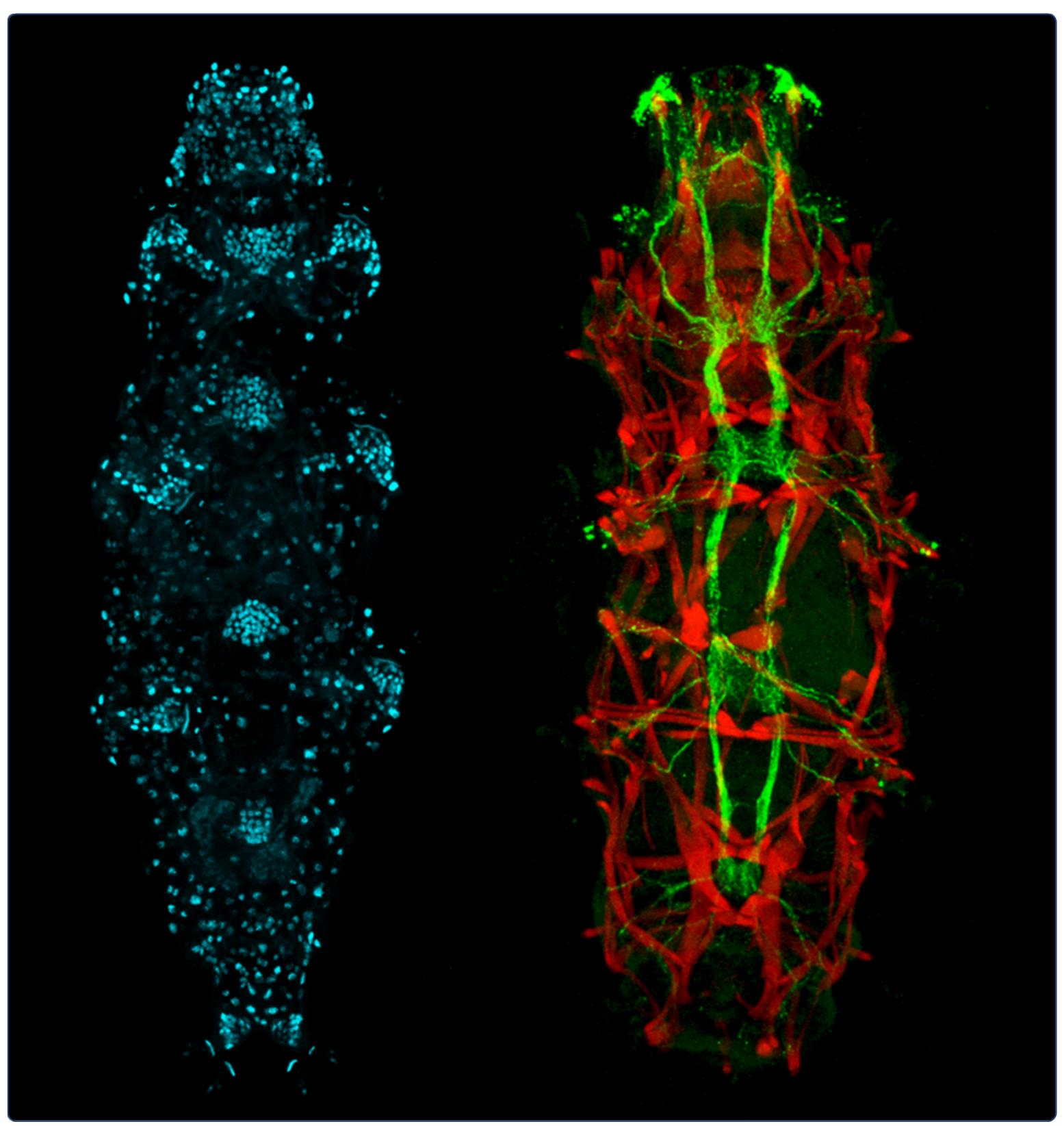

Selective neuronal staining in tardigrades and onychophorans provides insights into the evolution of segmental ganglia in panarthropods

Mayer et al.

C Biomed Central

Mayer et al. BMC Evolutionary Biology 2013, 13:230

http://www.biomedcentral.com/1471-2148/13/230 


\title{
Selective neuronal staining in tardigrades and onychophorans provides insights into the evolution of segmental ganglia in panarthropods
}

\author{
Georg Mayer ${ }^{1 *}$, Christine Martin', Jan Rüdiger', Susann Kauschke', Paul A Stevenson², Izabela Poprawa ${ }^{3}$, \\ Karin Hohberg ${ }^{4}$, Ralph O Schill, ${ }^{5}$ Hans-Joachim Pflüger ${ }^{6}$ and Martin Schlegel ${ }^{7,8}$
}

\begin{abstract}
Background: Although molecular analyses have contributed to a better resolution of the animal tree of life, the phylogenetic position of tardigrades (water bears) is still controversial, as they have been united alternatively with nematodes, arthropods, onychophorans (velvet worms), or onychophorans plus arthropods. Depending on the hypothesis favoured, segmental ganglia in tardigrades and arthropods might either have evolved independently, or they might well be homologous, suggesting that they were either lost in onychophorans or are a synapomorphy of tardigrades and arthropods. To evaluate these alternatives, we analysed the organisation of the nervous system in three tardigrade species using antisera directed against tyrosinated and acetylated tubulin, the amine transmitter serotonin, and the invertebrate neuropeptides FMRFamide, allatostatin and perisulfakinin. In addition, we performed retrograde staining of nerves in the onychophoran Euperipatoides rowelli in order to compare the serial locations of motor neurons within the nervous system relative to the appendages they serve in arthropods, tardigrades and onychophorans.
\end{abstract}

Results: Contrary to a previous report from a Macrobiotus species, our immunocytochemical and electron microscopic data revealed contralateral fibres and bundles of neurites in each trunk ganglion of three tardigrade species, including Macrobiotus cf. harmsworthi, Paramacrobiotus richtersi and Hypsibius dujardini. Moreover, we identified additional, extra-ganglionic commissures in the interpedal regions bridging the paired longitudinal connectives. Within the ganglia we found serially repeated sets of serotonin- and RFamid-like immunoreactive neurons. Furthermore, our data show that the trunk ganglia of tardigrades, which include the somata of motor neurons, are shifted anteriorly with respect to each corresponding leg pair, whereas no such shift is evident in the arrangement of motor neurons in the onychophoran nerve cords.

Conclusions: Taken together, these data reveal three major correspondences between the segmental ganglia of tardigrades and arthropods, including (i) contralateral projections and commissures in each ganglion, (ii) segmentally repeated sets of immunoreactive neurons, and (iii) an anteriorly shifted (parasegmental) position of ganglia. These correspondences support the homology of segmental ganglia in tardigrades and arthropods, suggesting that these structures were either lost in Onychophora or, alternatively, evolved in the tardigrade/ arthropod lineage.

Keywords: Arthropoda, Ecdysozoa, Nervous system, Onychophora, Panarthropoda, Segmental ganglia, Synapomorphy, Tardigrada

\footnotetext{
*Correspondence: gmayer@onychophora.com

'Animal Evolution and Development, Institute of Biology, University of

Leipzig, Talstraße 33, D-04103 Leipzig, Germany

Full list of author information is available at the end of the article
} 


\section{Background}

The phylogenetic position of tardigrades is controversial, as they are typically regarded as either the sister group of arthropods, onychophorans, onychophorans plus arthropods, or one of the cycloneuralian taxa, such as nematodes [1-16]. Incongruent topologies based on molecular datasets suggest that Tardigrada is a rogue taxon, the phylogenetic position of which is uncertain (Figure 1A). The problem with molecular phylogenetic approaches might be due to long-branch attraction artefacts, which have been shown to either directly or indirectly affect the inferred topologies [17-19]. These artefacts might have caused the conflicting hypotheses on the position of Tardigrada in different molecular phylogenetic studies [2,4,11-13]. Hence, to rely entirely on molecular datasets may be insufficient when trying to resolve the phylogenetic position of tardigrades within the Ecdysozoa.

An alternative approach to discern the phylogenetic relationships between different animal groups is the comparison of their anatomy, including the organisation of their nervous systems $[20,21]$. One of the most prominent features of the tardigrade nervous system is the presence of segmentally repeated ganglia in their ventral nervous system [22-25]. The ganglia are accumulations of neuronal cell bodies, which are linked by somata-free connectives along the body [21]. Among representatives of Panarthropoda (Onychophora + Tardigrada + Arthropoda), segmental ganglia occur only in arthropods and tardigrades, whereas somata-free connectives and segmental ganglia are lacking in onychophorans, which instead show a medullary organisation of their ventral nerve cords [8,26-28]. Thus, the question arises of whether segmental ganglia evolved convergently in tardigrades and arthropods, or whether they are homologous structures (Figure $1 \mathrm{~B}-\mathrm{H}$ ). If they are indeed homologous, they might either have been present in the last common ancestor of Panarthropoda or even Ecdysozoa (albeit reduced in Onychophora [12]), or they might represent a synapomorphy uniting the tardigrades and arthropods [8].

To clarify this issue and shed light on the evolution of segmental ganglia, we have chosen two approaches. On the one hand, we searched for specific correspondences between the tardigrade and arthropod ganglia by analysing the staining patterns of a variety of established neuronal markers, including antisera raised against tyrosinated and acetylated $\alpha$-tubulin (a component of neurotubules), the biogenic amine serotonin and the neuropeptides RFamide, allatostatin and perisulfakinin. On the other hand, we performed retrograde dye tracing of leg nerves in the onychophoran Euperipatoides rowelli to localise the cell bodies of motor neurons supplying the legs. This approach was necessary to allow a comparison with tardigrades and arthropods because segmental ganglia are lacking in onychophorans and the leg nerves are the most prominent
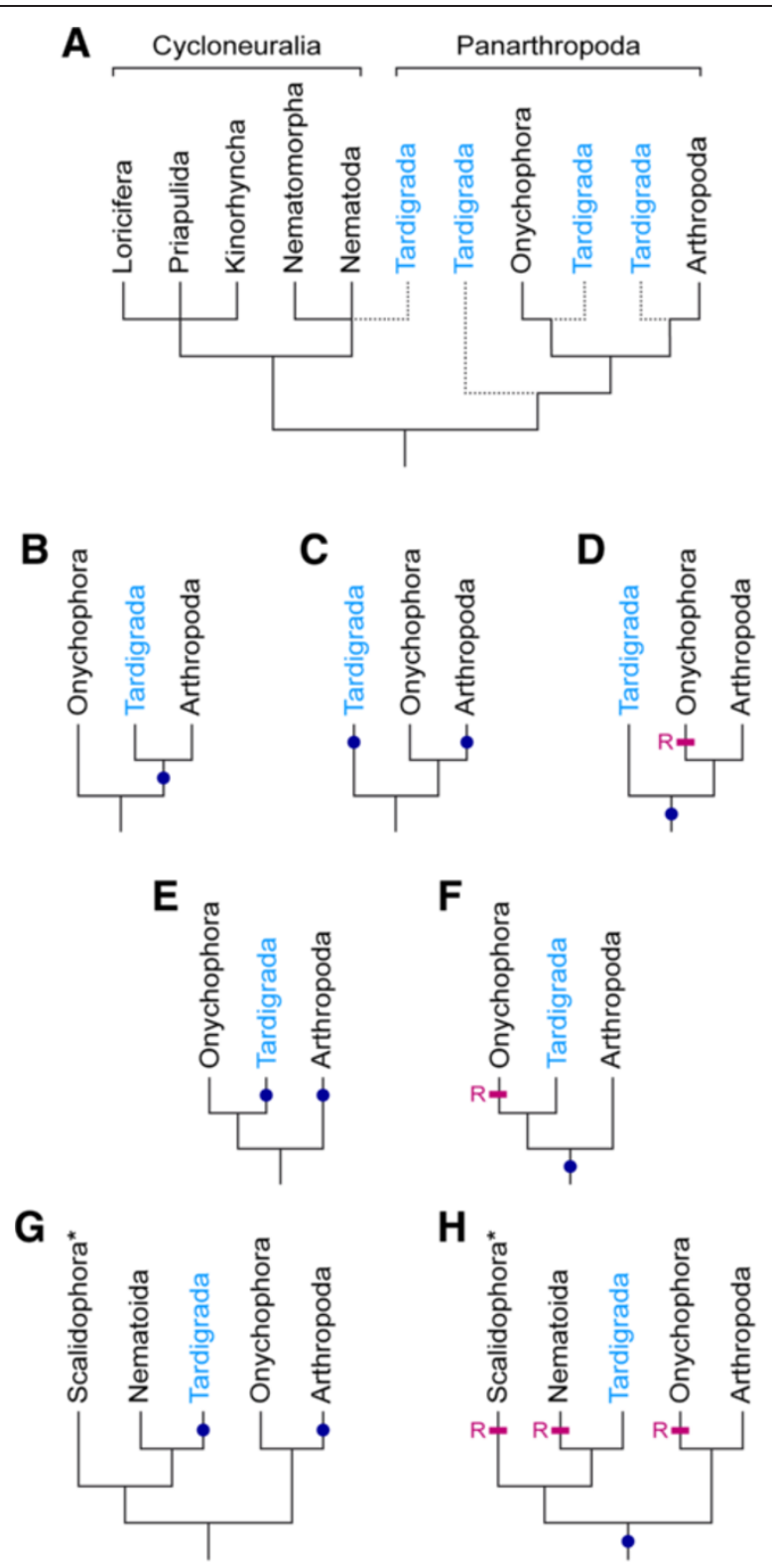

Figure 1 Alternative hypotheses on the phylogenetic position of the Tardigrada within the Ecdysozoa and the evolution of segmental ganglia. (A) Tree illustrating controversial views on the phylogenetic position of tardigrades as either the sister group of arthropods, onychophorans, onychophorans plus arthropods, or one of the cycloneuralian taxa (modified from ref. [8]). (B-H) Alternative scenarios on the evolution of segmental ganglia (dark-blue dots) in panarthropods, depending on the phylogenetic position of tardigrades favoured. Segmental ganglia might be either homologous structures $(\mathbf{B}, \mathbf{D}, \mathbf{F}, \mathbf{H})$ or they might have evolved independently in tardigrades and arthropods $(\mathbf{C}, \mathbf{E}, \mathbf{G})$. The scenario in $\mathbf{B}$ is most parsimonious, whereas those in $\mathbf{D}, \mathbf{F}$ and $\mathbf{H}$ require additional losses (magenta bars with an " $\mathrm{R}^{\prime}$ ) in onychophorans and/or other ecdysozoans. Asterisks in $\mathbf{G}$ and $\mathbf{H}$ indicate that a ventral chain of ganglia-like thickenings also occurs in kinorhynchs, although their homology with segmental ganglia of tardigrades and arthropods is uncertain (see text for further details). 
segmental structures associated with nerve cords in these animals $[8,26-28]$.

\section{Results}

Organisation of the central and peripheral nervous system in the three tardigrade species studied

The three tardigrade species studied, including Macrobiotus cf. harmsworthi, Paramacrobiotus richtersi and Hypsibius dujardini, show basically the same organisation of the central nervous system, with the brain and the four trunk ganglia being the most prominent features (Figures 2A-D and 3 ). The brain comprises a dorsal, bilaterally symmetric ganglion, which bears a central neuropil and a defined number of serotonin-like $(\mathrm{n} \cong 14)$, RFamide-like $(\mathrm{n} \cong 26)$, allatostatin-like $(\mathrm{n} \cong 12)$ and perisulfakinin-like $(\mathrm{n}=2) \mathrm{im}$ munoreactive somata (see ref. [24] for further details on the architecture of the brain in Macrobiotus cf. harmsworthi). The brain is linked to the first trunk ganglion via an inner and an outer pair of connectives, whereas the trunk ganglia are joined with each other by only one pair of connectives along the body (Figures 2C, D, 3 and 4A, B). The first three ganglia are similar in size, whereas the fourth ganglion is smaller and contains fewer cells, as revealed by DNA labelling (Figures $2 \mathrm{~B}$ and 3 ).

Each trunk ganglion consists of two hemiganglia that are fused along the ventral midline and show a central fibre mass (Figures 3, 4A-C and 5A). Within this mass, a clear structure of fibre arrangement is not apparent. However, commissure-like bundles of contralateral neurites are present, some of which display serotonin-like, RFamide-like, allatostatin-like and perisulfakinin-like immunoreactivity (Figures 3, 4A, B and 5A-D). In addition to these fibres and bundles of neurites, each trunk ganglion displays a set of serotonin-like and RFamide-like immunoreactive cell bodies that are organised in a bilaterally symmetric pattern and show essentially the same arrangement in different specimens of the same species (arrowheads in Figure 3 and Additional file 1).

Apart from contralateral projections and commissure-like structures within each ganglion, additional extra-ganglionic (=interpedal) commissures occur anterior to the second, third and fourth trunk ganglia (arrowheads in Figures 4A, B, $5 \mathrm{~A}$ and Additional file 2). These interpedal commissures are not accompanied by neuronal cell bodies, as they are not associated with ganglia but link the connectives, which are somata-free. Each interpedal commissure consists of a bundle of fibres, which in contrast to those in the connectives do not show serotonin-like, RFamide-like, allatostatin-like or perisulfakinin-like immunoreactivity (Figures 4D, 5A and Additional file 3, Additional file 4, Additional file 5, Additional file 6).

Each trunk ganglion gives rise to two pairs of leg nerves, one anterior pair and a posterior pair that project posterolaterally into the legs (Figures 4A, B, 5A, 6C, 7 and 8A, B). This peculiar posterior course of the leg nerves is due to an anteriorly shifted position of each trunk ganglion with
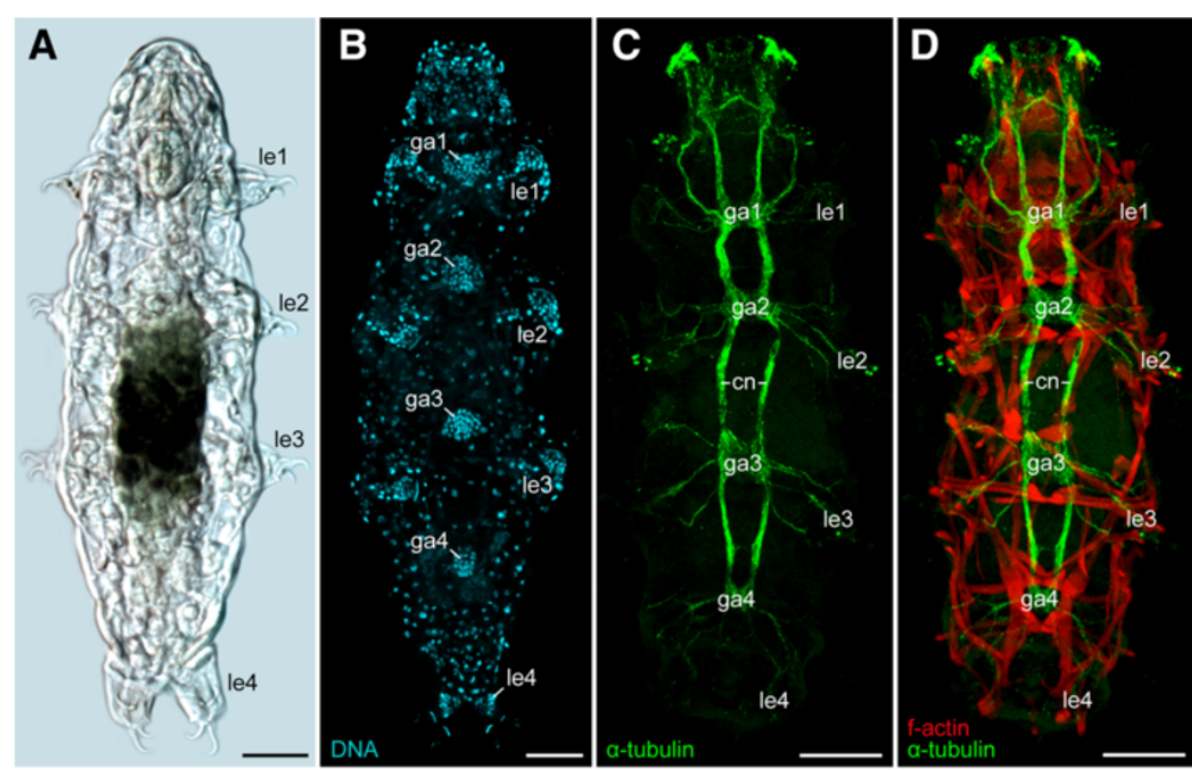

Figure 2 General anatomy and organisation of the ventral nervous system and position of trunk ganglia in tardigrades. (A) Light micrograph of a specimen of Hypsibius dujardini in dorsal view. (B-D) Confocal micrographs of Macrobiotus cf. harmsworthi specimens (ventral view, anterior is up). Note the anteriorly shifted position of the four trunk ganglia with respect to each leg pair. (B) DNA labelling of cell nuclei (SYBR ${ }^{\circledast}$ Green). (C) Combined anti-tyrosinated and anti-acetylated a-tubulin immunolabelling to reveal nerve tracts. (D) Combined anti-tyrosinated and anti-acetylated a-tubulin immunolabelling (green) and phalloidin-rhodamine staining (red) to reveal the musculature (same specimen as in C). Abbreviations: cn, somata-free connectives; ga1-ga4, trunk ganglia 1 to 4; le1-le4, walking legs 1 to 4. Scale bars: 25 m (A-D). 


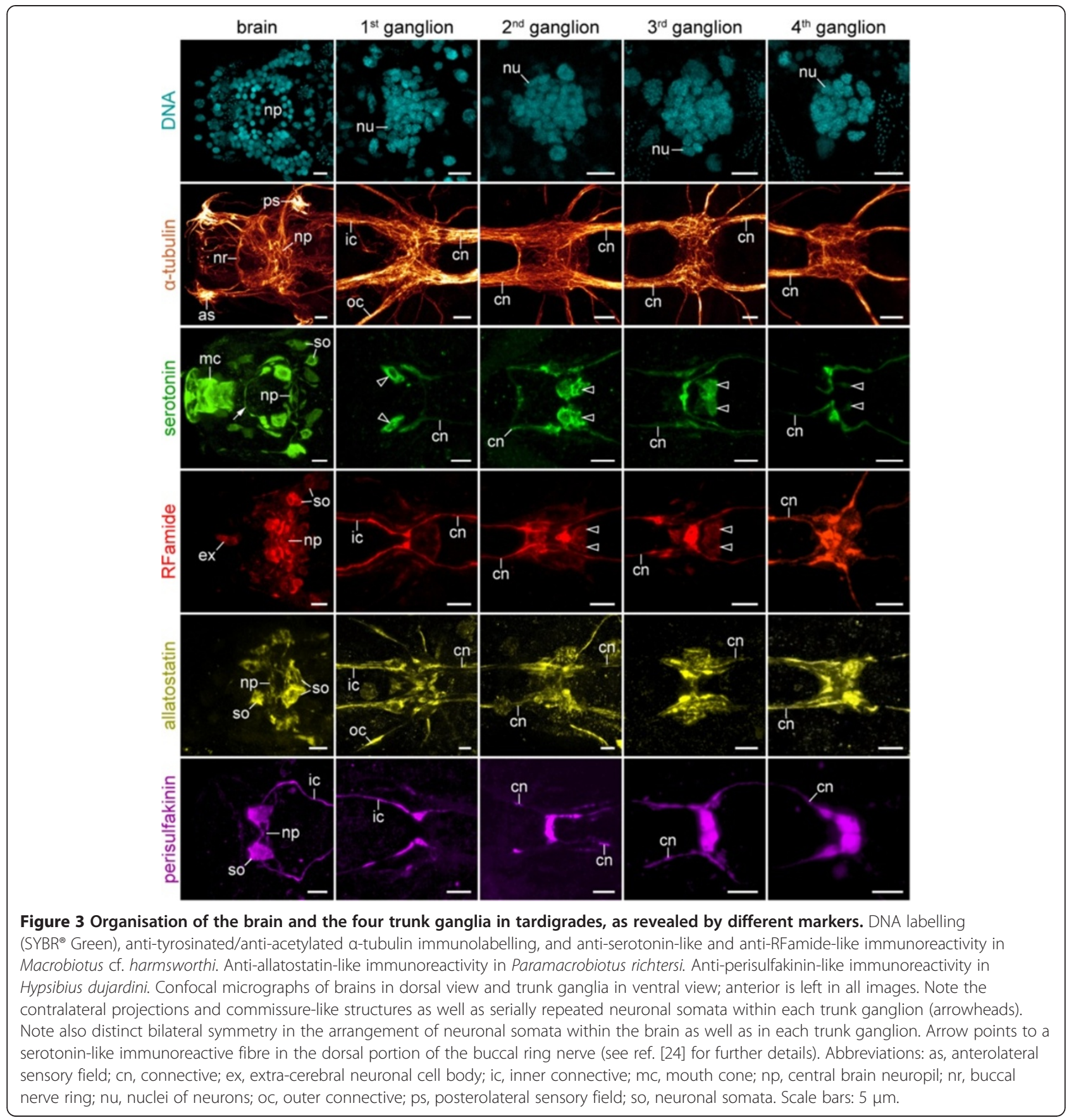

respect to the corresponding leg pairs (Figure 2B-D and Additional file 2, Additional file 4). Though less evident in the first leg-bearing segment, this shift is clearly present in all trunk segments (Figure 6A and Additional file 4). Each leg nerve gives rise to additional branches and the anterior leg nerve is associated with a peripheral ganglion lying at the basis of each leg (Figures 5A, 6C, 7 and 8A, B). While the branching pattern of the leg nerves is similar in the first three leg pairs, the branches are part of a complex network in the fourth leg-bearing segment (Figures 5A-D, 6C, 7 and $8 \mathrm{~A}, \mathrm{~B}$ ). Among other tracts, this network contains a pair of nerves embracing the cloaca. These cloacal nerves terminate in two large, serotonin-like and allatostatin-like immunoreactive, platelet-shaped structures devoid of nuclei (Figure 5B, C and Additional file 5). Moreover, they are associated with two RFamide-like immunoreactive cell bodies (arrows in Figure 5D and Additional file 4).

Additional peripheral tracts form an orthogon-like grid encompassing the body and consisting of two pairs of longitudinal and four pairs of transverse tracts linked to 

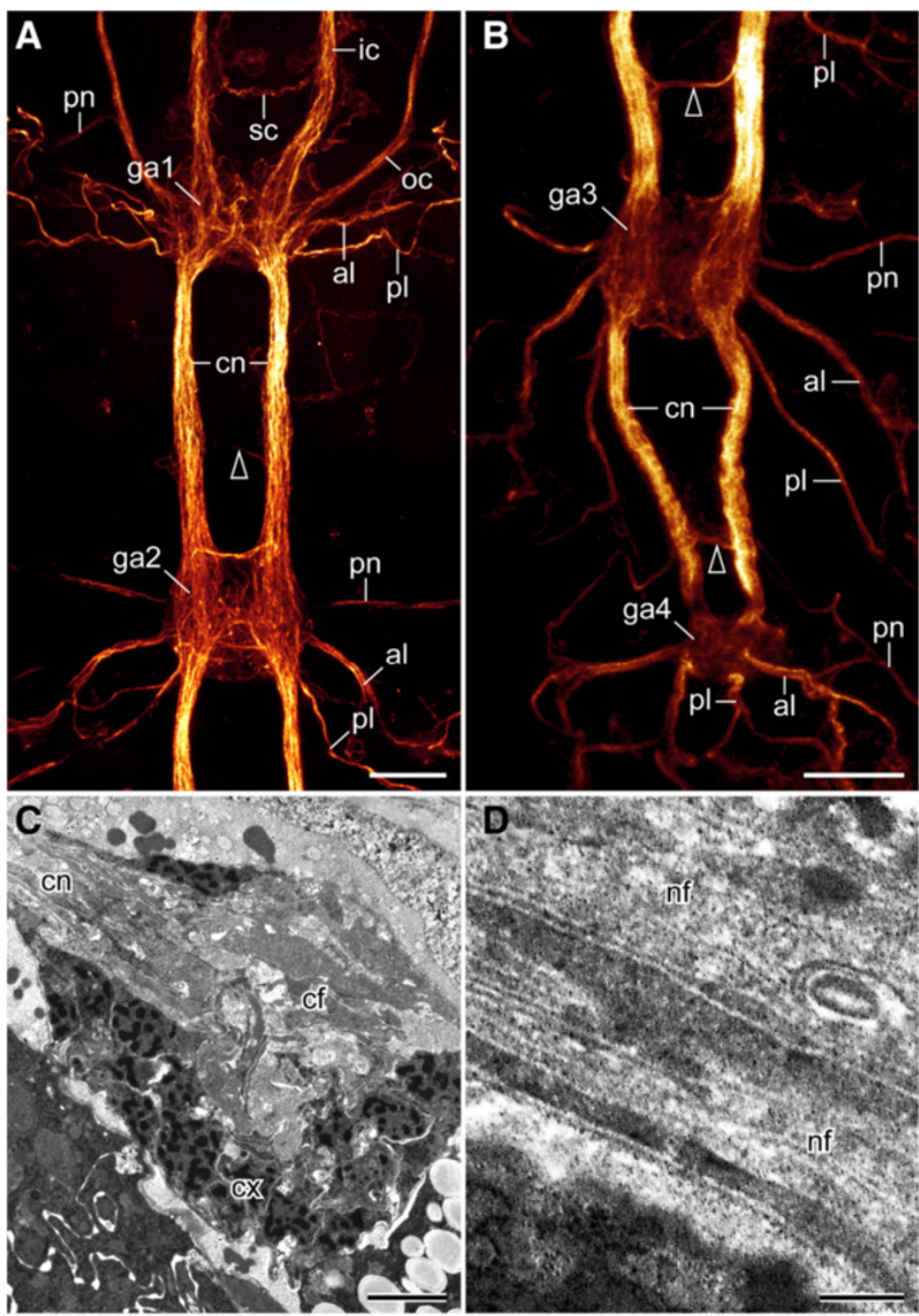

Figure 4 Organisation of the tardigrade ventral nervous system. Note the extra-ganglionic, interpedal commissures in front of the second, third and fourth trunk ganglia (arrowheads in $\mathbf{A}$ and $\mathbf{B}$ ). Combined anti-tyrosinated and anti-acetylated a-tubulin immunolabelling, confocal micrographs (A, B) and transmission electron micrographs (C, D) from Macrobiotus cf. harmsworthi. (A) Detail of the anterior portion of the ventral nervous system. Anterior is up. (B) Detail of the posterior portion of the ventral nervous system. Anterior is up. (C) Oblique sagittal section of a trunk ganglion showing the central fibre mass. Anterior is in the upper left corner. (D) Transverse section of an interpedal commissure. Abbreviations: al, anterior leg nerve; cf, central fibre mass; $\mathrm{Cn}$, connective; $\mathrm{Cx}$, cortex; gal-ga4, trunk ganglia 1 to 4; ic, inner connective; $\mathrm{nf}$, nerve fibre; oc, outer connective; pl, posterior leg nerve; pn, peripheral nerve; sc, commissure of the stomodeal complex. Scale bars: $10 \mu \mathrm{m}$ (A, B), $2 \mu \mathrm{m}$ (C) and $250 \mathrm{~nm}$ (D).

each other (Figures $6 \mathrm{~A}-\mathrm{C}, 7$ and $8 \mathrm{~A}, \mathrm{~B})$. The first pair of transverse peripheral nerves is associated with the outer connectives, whereas the second and the third pairs project laterally from the second and third trunk ganglia. The fourth pair is part of the anastomosing network of peripheral tracts in the fourth leg-bearing segment (Figures 5A, 6C and 8A). The lateral pair of longitudinal tracts interconnects the transverse peripheral nerves on each side of the body, whereas the dorsolateral pair of longitudinal tracts runs further dorsally and is linked to the dorsomedian portion of the brain via a convergent pair of nerve tracts (Figure 7 and $8 \mathrm{~B}$ ).
Position of leg nerves and localisation of motor neurons in the onychophoran Euperipatoides rowelli

In contrast to the tardigrade nervous system, the nerve cords of the onychophoran Euperipatoides rowelli lack segmental ganglia and somata-free connectives (Figure 9A, B). The neuronal cell bodies are instead distributed along the entire nerve cord. Hence, there is no clear border delineating a defined neuromere. The only segmentally repeated structures associated with nerve cords are the paired nerves supplying each leg. As found for the three tardigrade species studied, each leg of the onychophoran E. rowelli is also innervated by an anterior and a posterior 

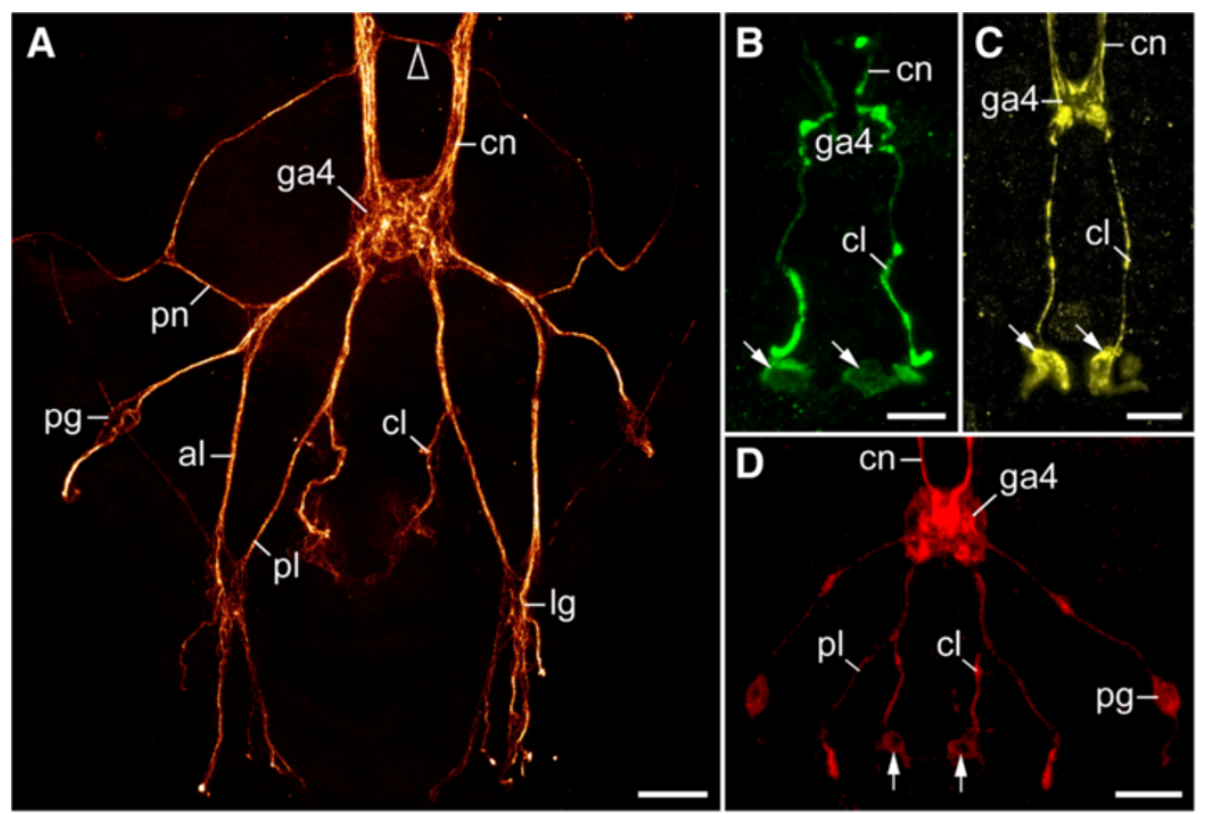

Figure 5 Organisation of the peripheral nervous system at the posterior end of tardigrades. Confocal micrographs from Macrobiotus $\mathrm{Cf}$. harmsworthi (A, B, D) and Paramacrobiotus richtersi (C). Anterior is up in all images. (A) Combined anti-tyrosinated and anti-acetylated a-tubulin immunolabelling. Arrowhead points to an extra-ganglionic, interpedal commissure in front of the fourth trunk ganglion. (B) Anti-serotonin-like immunoreactivity. Arrows point to the two platelet-shaped structures (=putative release sites) associated with cloacal nerves. (C) Anti-allatostatin-like immunoreactivity. Arrows point to the two platelet-shaped structures associated with cloacal nerves. (D) Anti-RFamide-like immunoreactivity. Arrows point to the somata of immunoreactive neurons associated with cloacal nerves. Abbreviations: al, anterior leg nerve; $\mathrm{Cl}$, cloacal nerve; $\mathrm{Cn}$, connective; ga4, fourth trunk ganglion; lg, leg ganglion; pg, peripheral ganglion; pl, posterior leg nerve; pn, peripheral nerve. Scale bars: $10 \mu \mathrm{m}$ (A, C) and $5 \mu \mathrm{m}$ (B).

leg nerve (Figure 9C). However, in contrast to the tardigrade nervous system, the bases of the two leg nerves are not shifted anteriorly but take a direct lateral course into each leg (Figure 9A-C).

The cell bodies of motor neurons in Euperipatoides rowelli could nonetheless still be shifted anteriorly, as in tardigrades (Figure 10A). To clarify this, we performed retrograde fills of the leg nerves using dextran coupled to tetramethylrhodamine. Our data show that the cell bodies of locomotory neurons innervating the onychophoran legs are grouped around the roots of the two leg nerves (Figure 10B-D). Thus, in contrast to the ventral nervous system of tardigrades, neither the bases of leg nerves nor the cell bodies of motor neurons are shifted anteriorly with respect to each leg pair in onychophorans.

\section{Discussion}

Interpedal commissures and grid-like arrangement of peripheral nerves: Remnants of an ancestral orthogonal nervous system?

Previous studies have shown that an orthogonal organisation of the nervous system, characterised by a regular grid of longitudinal tracts interconnected by numerous ring commissures, was most likely present in the last common ancestor of panarthropods, as it occurs in various invertebrates, including the onychophorans $[8,27,28]$. Thus, the ganglionated, "rope ladder-like" nervous system of arthropods might have evolved from such an ancestral orthogonal architecture. This hypothesis receives support from our data, as we observed a regular, grid-like arrangement of longitudinal and transverse peripheral tracts in the tardigrade nervous system. Although the transverse tracts do not form complete rings, together with the paired lateral and dorsolateral nerve tracts, they might be remnants of an ancestral orthogonal arrangement, which might have been present in the last common ancestor of Panarthropoda [27,28].

Furthermore, our data revealed additional commissures in the ventral nervous system of the three tardigrade species studied, which lie outside the trunk ganglia, in the interpedal regions, where they link the paired longitudinal connectives with each other (Figure 11). Although these commissures have long been known from tardigrades [29-31], Marcus [22] questioned their neural identity in his monograph, which might have been the reason why these commissures were neglected by most subsequent authors (but see ref. [25]). Nevertheless, our data clearly show that the interpedal commissures belong to the ventral nervous system of tardigrades. These commissures might be remnants of numerous median commissures, which were present in the pedal and interpedal regions in the last common ancestor of Panarthropoda and have persisted in 


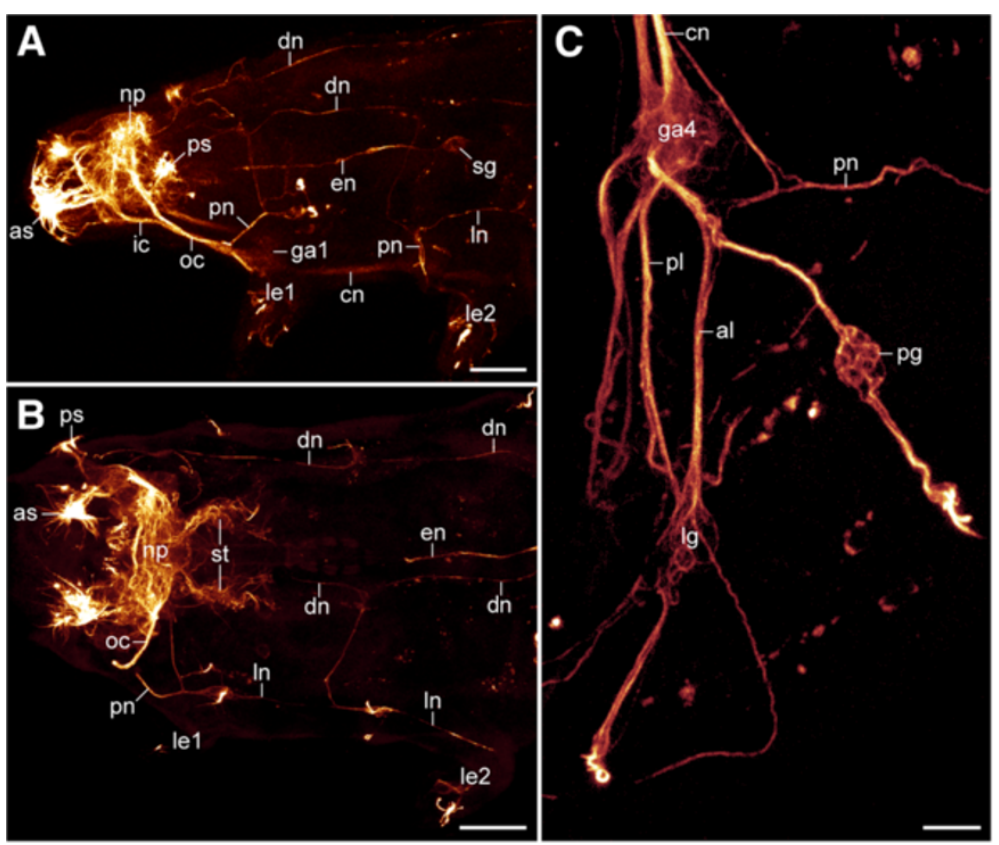

Figure 6 Organisation of the peripheral nervous system in the tardigrade Macrobiotus cf. harmsworthi. Combined anti-tyrosinated and anti-acetylated a-tubulin immunolabelling. Confocal micrographs. (A) Anterior body half of a specimen in lateral view (anterior is left).

(B) Anterior body half of a specimen in dorsolateral view (anterior is left). (C) Posterior body region of a specimen in lateral view (anterior is up). Abbreviations: al, anterior leg nerve; as, anterolateral sensory field; cn, connective; dn, dorsolateral nerve tract; en, oesophageal neurite; ga1, first trunk ganglion; ga4, fourth trunk ganglion; ic, inner connective; le1-le2, position of legs 1 and 2; lg, leg ganglion; In, lateral nerve tract; np, central brain neuropil; oc, outer connective; pg, peripheral ganglion; pl, posterior leg nerve; pn, peripheral nerve; ps, posterolateral sensory field; sg, stomatogastric ganglion; st, neurite bundles innervating the stylet musculature. Scale bars: $20 \mu \mathrm{m}$ (A, B) and 5 m (C).

extant onychophorans [8,26-28], whereas they were reduced completely in arthropods (Figure 11 ).

\section{Evidence for the homology of segmental ganglia in tardigrades and arthropods}

A previous immunocytochemical study [32] has suggested that the organisation of the trunk ganglia in the tardigrade Macrobiotus hufelandi is principally different from that in arthropods, on the grounds that no contralateral projections or commissures linking the two hemiganglia were detected. Based on this finding, the contralateral commissures have been reinterpreted as a derived feature (=synapomorphy) of Onychophora and Arthropoda to the exclusion of Tardigrada [33]. However, our immunocytochemical and electron microscopic data clearly show contralateral fibres and bundles of neurites in all four trunk ganglia in specimens of Macrobiotus cf. harmsworthi, Paramacrobiotus richtersi and Hypsibius dujardini, thus confirming previous findings from other tardigrade species, including Macrobiotus hufelandi [22,23,25,34]. Therefore, contrary to this previous assumption [33], the occurrence of contralateral fibres and commissures in the ventral nervous system does not support the proposed sister group relationship of Onychophora and Arthropoda, as these structures also occur in the tardigrade ganglia and, therefore, were most likely present in the last common ancestor of Panarthropoda.

Likewise, the segmental sets of serotonergic neurons occurring in the ventral ganglia of chelicerates, myriapods, crustaceans and insects [35] have been regarded as a derived feature (=autapomorphy) of Arthropoda [33]. They were unknown in tardigrades, while in onychophorans serotonin-like immunoreactive somata are distributed throughout each nerve cord [26,27]. However, our results show that segmentally repeated sets of serotonin-like immunoreactive (and other) neurons are indeed present in the tardigrade ganglia, suggesting that they are either a synapomorphy of tardigrades and arthropods or an ancestral feature of Panarthropoda rather than an autapomorphy of Arthropoda [33].

Moreover, our data revealed an anteriorly shifted position of trunk ganglia with respect to each leg pair in the three tardigrade species studied, which is also seen in the illustrations of other tardigrade species [22,23,25,29-32,36,37]. Notably, a corresponding anterior shift in position of ganglia occurs in representatives of all major arthropod groups [38], which might be due to the embryonic origin of ganglia. During embryogenesis, the formation of ganglia coincides with parasegments, the initial functional units of the arthropod embryo, which are shifted anteriorly with 


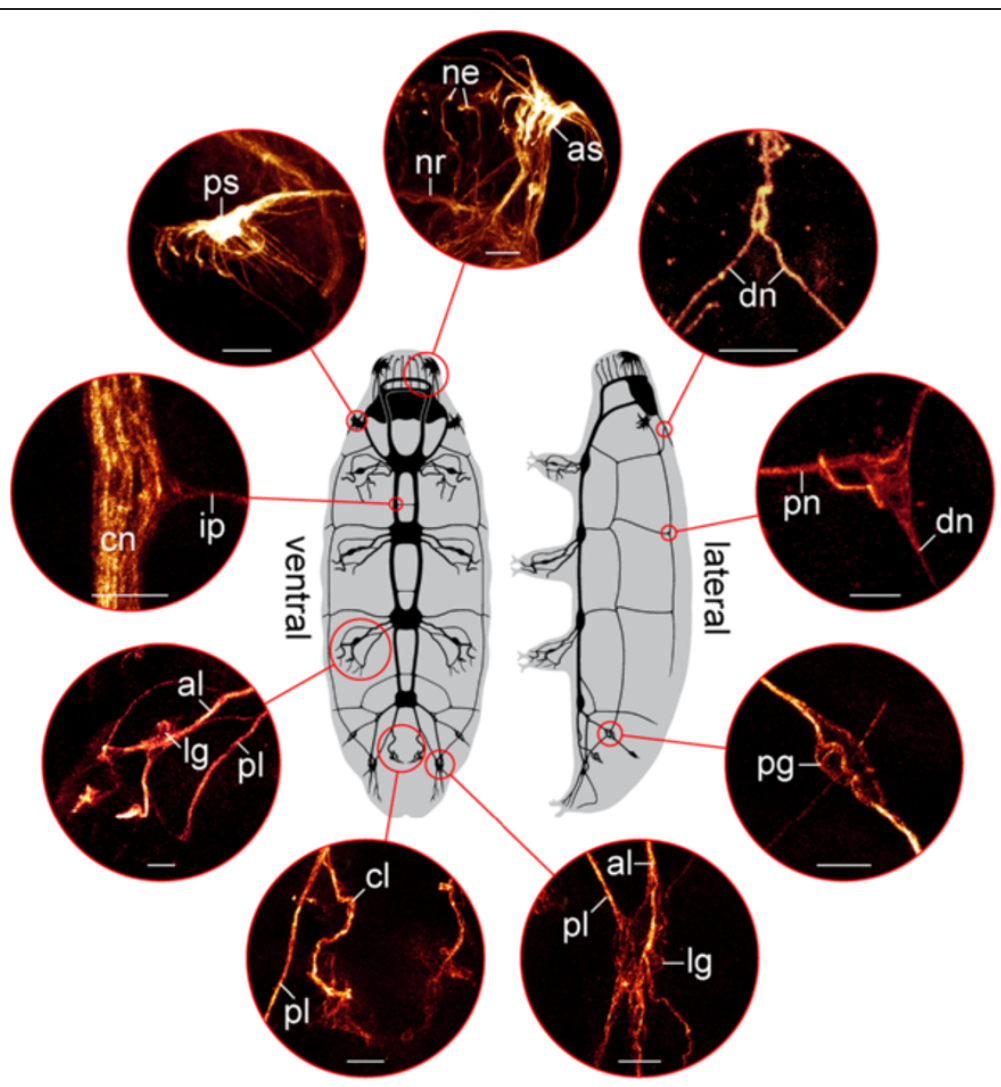

Figure 7 Organisation of the tardigrade nervous system. Diagrams in the centre illustrate specimens of the tardigrade Macrobiotus cf. harmsworthi in ventral and lateral views (anterior is up). Nerve tracts are indicated in black. Circular insets show details (confocal micrographs) of the nervous system based on anti-tyrosinated and anti-acetylated a-tubulin immunolabelling. Abbreviations: al, anterior leg nerve; as, anterolateral sensory field; cl, cloacal nerves; cn, connective; dn, dorsolateral nerve tract; ip, interpedal commissure; lg, leg ganglion; ne, neurites supplying the peribuccal lamellae; $\mathrm{nr}$, nerve ring innervating the peribuccal lamellae; pg, peripheral ganglion; pl, posterior leg nerve; pn, peripheral nerve; ps, posterolateral sensory field. Scale bars: $5 \mu \mathrm{m}$

respect to the adult segments [38,39]. At the end of embryogenesis, the ganglia retain their anteriorly shifted, parasegmental arrangement, whereas the position of other organs, including the legs, corresponds to the adult segments [38]. Consequently, the characteristic, anteriorly shifted position of ganglia can be taken as evidence of parasegments in tardigrades.

This assumption receives support from the expression pattern of the Engrailed protein in the tardigrade embryo, which is localised in the posterior ectoderm of each segment, thus resembling the situation in arthropods [40]. This suggests that the segment polarity gene engrailed has a conserved function in establishing the morphological boundaries between segments in both tardigrades and arthropods. In contrast, engrailed might play a different role in Onychophora, as the early expression domain of this gene extends beyond the segmental furrow and no precise cellular boundary is evident between engrailed and wingless domains in the onychophoran embryo [41].

Furthermore, the results of our neuronal tracing experiments using retrograde fills revealed no anterior shift in position of neurons supplying the legs in the onychophoran Euperipatoides rowelli, which would be expected, if parasegments were present (cf. diagrams in Figure 10A, B). To our knowledge, there is no indication of a similar anterior shift of neurons in any other group of segmented or "pseudosegmented" protostomes such as the kinorhynchs and annelids, since their ganglia are typically located either midway or even posteriorly within each segment [42-47]. Thus, irrespective of whether the segmental ganglia are homologous across these distantly related protostome taxa, their anteriorly shifted (i.e., parasegmental) position in each segment is unique to tardigrades and arthropods, suggesting that these structures are unlikely to have evolved independently in these two animal groups (Figure 1C, E, G).

Hence, the ventral chain of ganglia in a parasegmental position is either a synapomorphy of Tardigrada and Arthropoda (Figure 1B), or it might have been lost in the onychophoran lineage (Figure 1D, F, H). We favour the first alternative, as any other scenario would require additional evolutionary steps and is therefore less parsimonious. In 

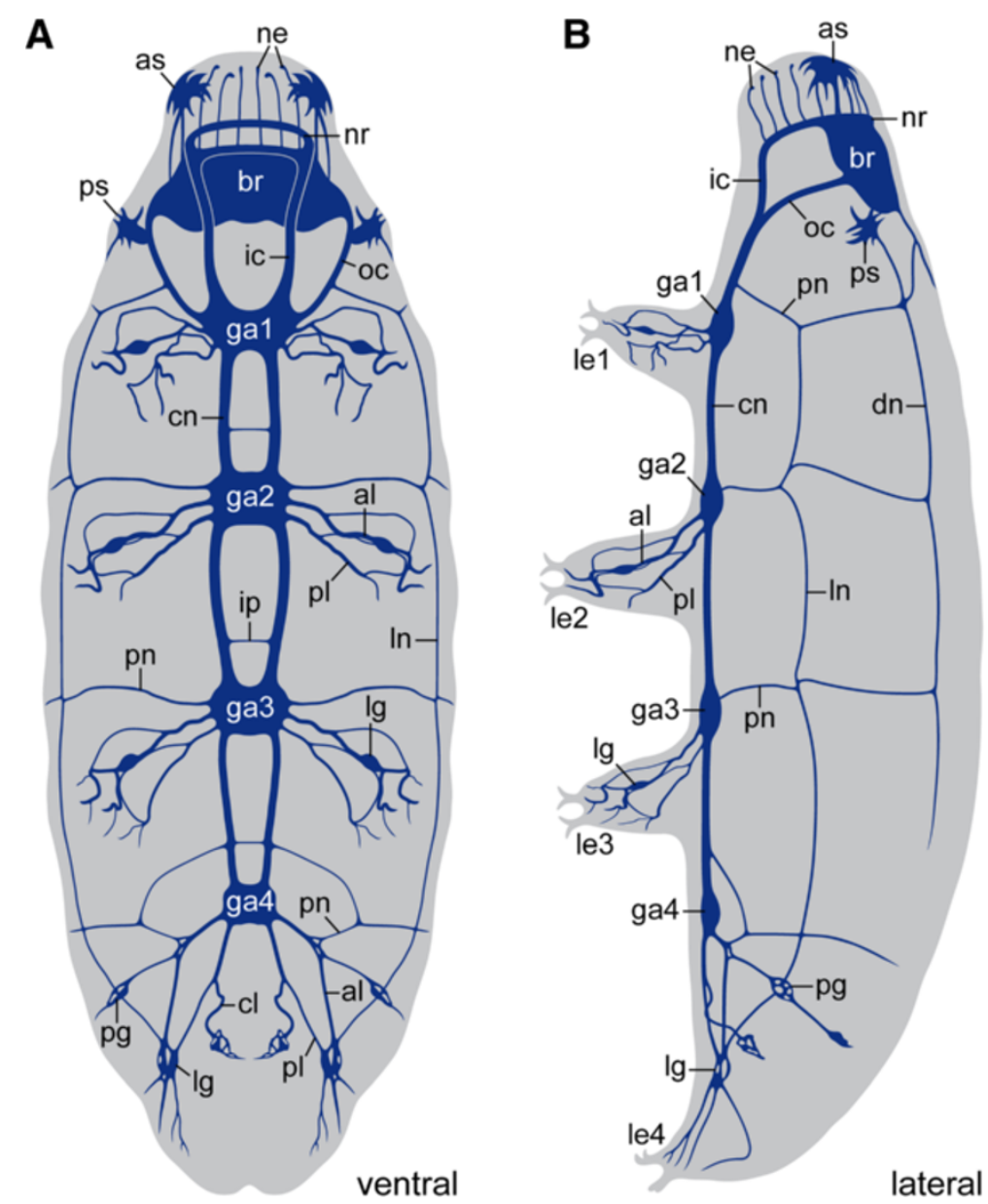

Figure 8 Diagrams showing the organisation of the tardigrade nervous system. Reconstructions of nerve tracts are based on anti-tubulin immunolabelling in Macrobiotus cf. harmsworthi. Anterior is up. (A) Ventral view. (B) Lateral view. Abbreviations: al, anterior leg nerve; as, anterolateral sensory field; br, brain; cl, cloacal nerves; cn, connective; dn, dorsolateral nerve tract; ga1-ga4, trunk ganglia 1 to 4; ic, inner connective; ip, interpedal commissure; le1-le4, legs 1 to 4; lg, leg ganglion; In, lateral nerve tract; ne, neurites supplying the peribuccal lamellae; $\mathrm{nr}$, nerve ring innervating the peribuccal lamellae; oc, outer connective; pg, peripheral ganglion; pl, posterior leg nerve; pn, peripheral nerve; ps, posterolateral sensory field.

particular, a modification of the ventral chain of ganglia into a pair of widely separated medullary nerve cords, which occur in onychophorans [26-28], cannot be explained by a simple loss of segmental ganglia. Rather, several modifications, including reversals back to ancestral states, would be required. First, the neuronal cell bodies, which had been accumulated to segmental ganglia, would have to be redispersed along each nerve cord (cf. Figure 11). Second, the nerve cords would have to be separated from each other secondarily to take up a ventrolateral position on each side of the body. Third, the median commissures would have to have lost their segmental arrangement and to be multiplied along the body. Fourth, the motor neurons supplying each leg would have to be relocated from an anteriorly shifted (parasegmental) to a position in the middle of each segment. Based on these arguments, we consider an evolutionary scenario, which first proposes the presence of segmental ganglia in onychophorans and then assumes a reversal back to the ancestral orthogonal, medullary organisation of their nervous system, as very unlikely.

\section{Conclusions}

Unfortunately, all too often morphological and embryological data are either dismissed or simply mapped on trees generated by using molecular methods. This is problematic, in particular if one is dealing with a long-branch taxon, such as Tardigrada, the position of which is ambiguous, as evidenced by conflicting topologies published each year $[2-4,7,10-13,16]$. In this case, a careful evaluation of morphological characters might prove helpful. We have shown here that tardigrades and arthropods share a parasegmental organisation of the nervous system, with anteriorly shifted ganglia relative to each leg pair. The ganglia are linked by 

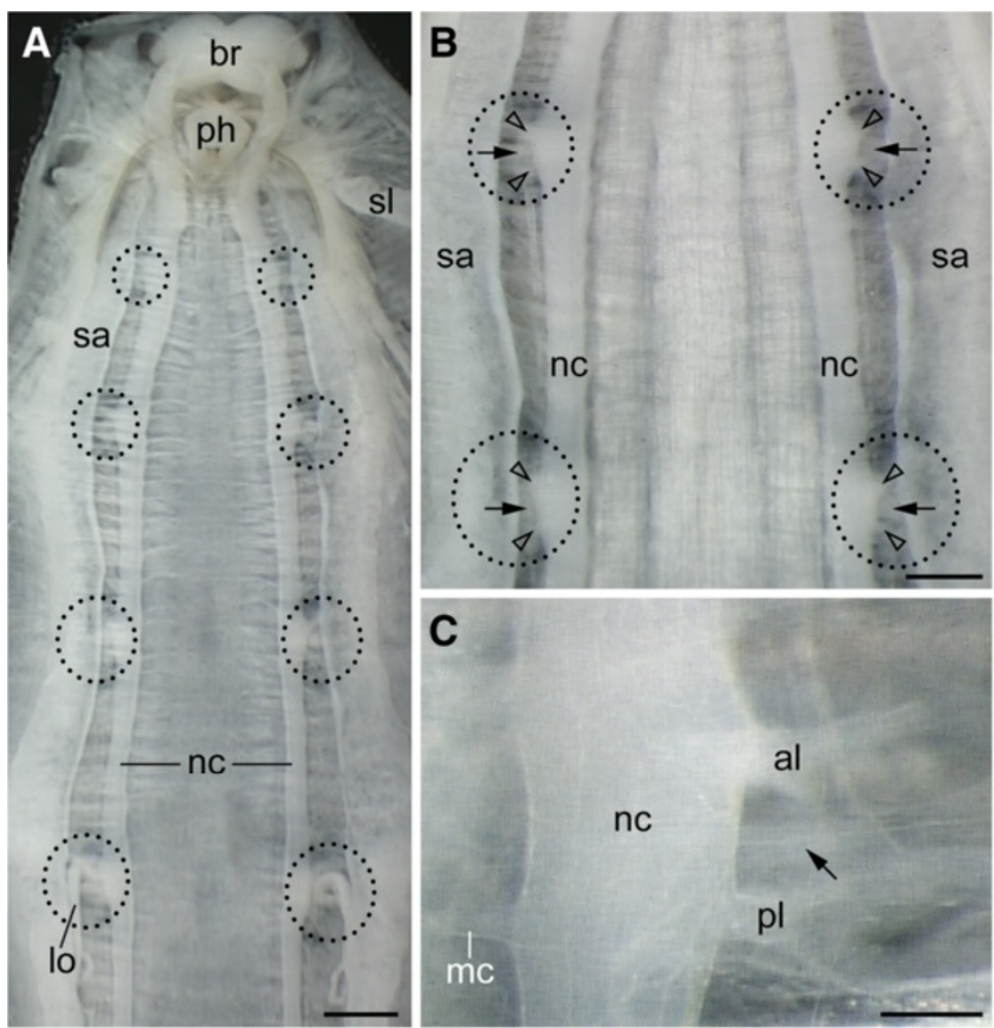

Figure 9 Organisation of the ventral nervous system and alignment of leg nerves in the onychophoran Euperipatoides rowelli. Light micrographs of a dissected specimen with removed digestive and genital tracts. Anterior is up. Arrows point to nephridial ducts. (A) Internal view of ventral body wall showing the position of legs (black dotted circles). (B) Detail of leg nerves (arrowheads) extending into each limb. (C) Detail of nerve cord showing the position of the anterior and posterior leg nerves. Abbreviations: al, anterior leg nerve; br, brain; lo, labyrinth organ (modified nephridium of the fourth leg-bearing segment); mc, median commissure; nc, nerve cord; ph, remnant of the pharynx; pl, posterior leg nerve; sa, salivary gland; sl, slime gland. Scale bars: $500 \mu \mathrm{m}$ (A), $300 \mu \mathrm{m}$ (B) and $100 \mu \mathrm{m}$ (C).

paired somata-free connectives along the body and the hemiganglia are joined by contralateral projections crossing the midline. Within the ganglia, segmentally repeated sets of serotonin-like (and other) immunoreactive neurons are found.

These neuroanatomical data speak in favour of the sister group relationship of Tardigrada and Arthropoda [1,8,16], i.e., the monophyly of Tactopoda [1], but contradict recent analyses of molecular data, which propose a sister group relationship of tardigrades either to Onychophora [11], to Nematoda [13], or to Onychophora plus Arthropoda [12]. The monophyly of Tactopoda receives additional support by the occurrence of stomatogastric ganglia associated with the third body segment in both tardigrades and arthropods, which are lacking in other animal groups [24]. Moreover, the segmentation of the longitudinal musculature might also support this relationship, as the longitudinal musculature does not show a segmental arrangement in onychophorans [48] and other ecdysozoans, except for kinorhynchs (a condition, which has been interpreted as derived in these animals [15,49-51]). In our view, therefore, it is premature to regard the position of Tardigrada as the sister group of
Onychophora and Arthropoda as "resolved" [12]. On the basis of our data, we instead suggest that the segmental ganglia are a synapomorphy uniting Tardigrada and Arthropoda to the exclusion of Onychophora.

\section{Methods}

\section{Specimens}

Specimens of Macrobiotus cf. harmsworthi Murray, 1907 (Eutardigrada, Macrobiotidae) were obtained from moss samples collected in the Volkspark Großdeuben near

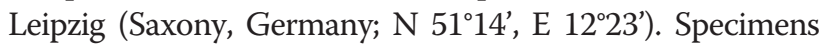
of Paramacrobiotus richtersi (Murray, 1911) (Eutardigrada, Macrobiotidae) were obtained from soils of the Berzdorf post-mining sites near Görlitz, Saxony, in April 1999, and cultured thenceforth as described previously [52]. Specimens of Hypsibius dujardini Doyère, 1840 (Eutardigrada, Hypsibiidae) were purchased from Sciento (Manchester, United Kingdom) and cultured in Petri dishes filled with commercial mineral water (Volvic). They were fed with algae (Chlorococcum sp.) once a month. Specimens of Euperipatoides rowelli Reid, 1996 (Onychophora, Peripatopsidae) were obtained from rotted logs in the 

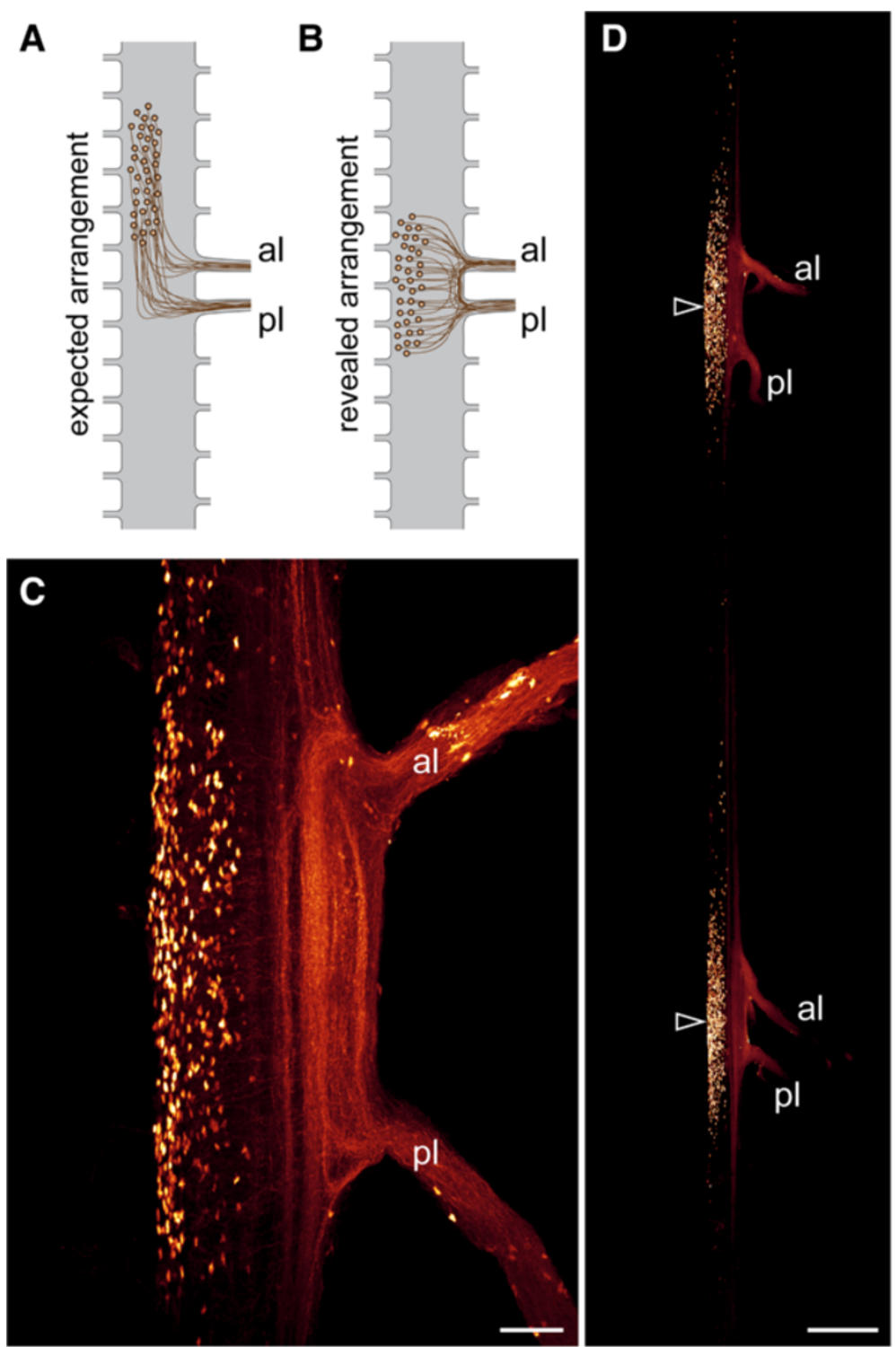

Figure 10 Retrograde tracing of motor neurons associated with leg nerves in the onychophoran Euperipatoides rowelli. (A) Diagram of expected, anteriorly shifted arrangement of neuronal cell bodies supplying the legs, if parasegments were present. (B) Diagram of revealed arrangement. Note that the neuronal cell bodies supplying the legs are not shifted anteriorly but lie next to the root of each leg nerve. (C, D) Retrograde fills of leg nerves with dextran coupled to tetramethylrhodamine in dissected nerve cords of the onychophoran Euperipatoides rowelli. Confocal micrographs. Note the position of neuronal cell bodies next to the roots of the leg nerves (arrowheads in $\mathbf{D}$ ). Abbreviations: al, anterior leg nerve; pl, posterior leg nerve. Scale bars: $50 \mu \mathrm{m}$ (C) and $250 \mu \mathrm{m}$ (D).

Tallaganda State Forest (New South Wales, Australia; $\left.\mathrm{S} 35^{\circ} 26^{\prime}, \mathrm{E} 149^{\circ} 33^{\prime}\right)$. The necessary permits for the collection of onychophorans were obtained from the Forestry Commission of New South Wales, Australia (Special Purposes Permit for Research no. XX51212).

\section{Histochemistry and immunocytochemistry on tardigrades} Immunocytochemistry was carried out as described previously [24]. As general markers of neural structures, we used two different antibodies that both stain $\alpha$-tubulin, a major component of axonal processes, either separately or in combination to increase the intensity of labelling. One antibody, anti-tyrosinated $\alpha$-tubulin (Sigma-Aldrich, St. Louis, MO, USA; diluted 1:200), is a monoclonal antibody raised in mice against a synthetic peptide (T13) containing $11 \mathrm{C}$-terminal amino acids of $\alpha$-tubulin from porcine brain plus an additional $\mathrm{N}$ terminal lysine and a $\mathrm{C}$-terminal tyrosine at the C-terminus [53,54]. The second antibody, anti-acetylated $\alpha$-tubulin (Sigma-Aldrich; diluted 1:500), is also a mouse monoclonal antibody, but directed against acetylated $\alpha$-tubulin from the outer arm of the sea urchin Strongylocentrotus purpuratus. This antibody recognises 


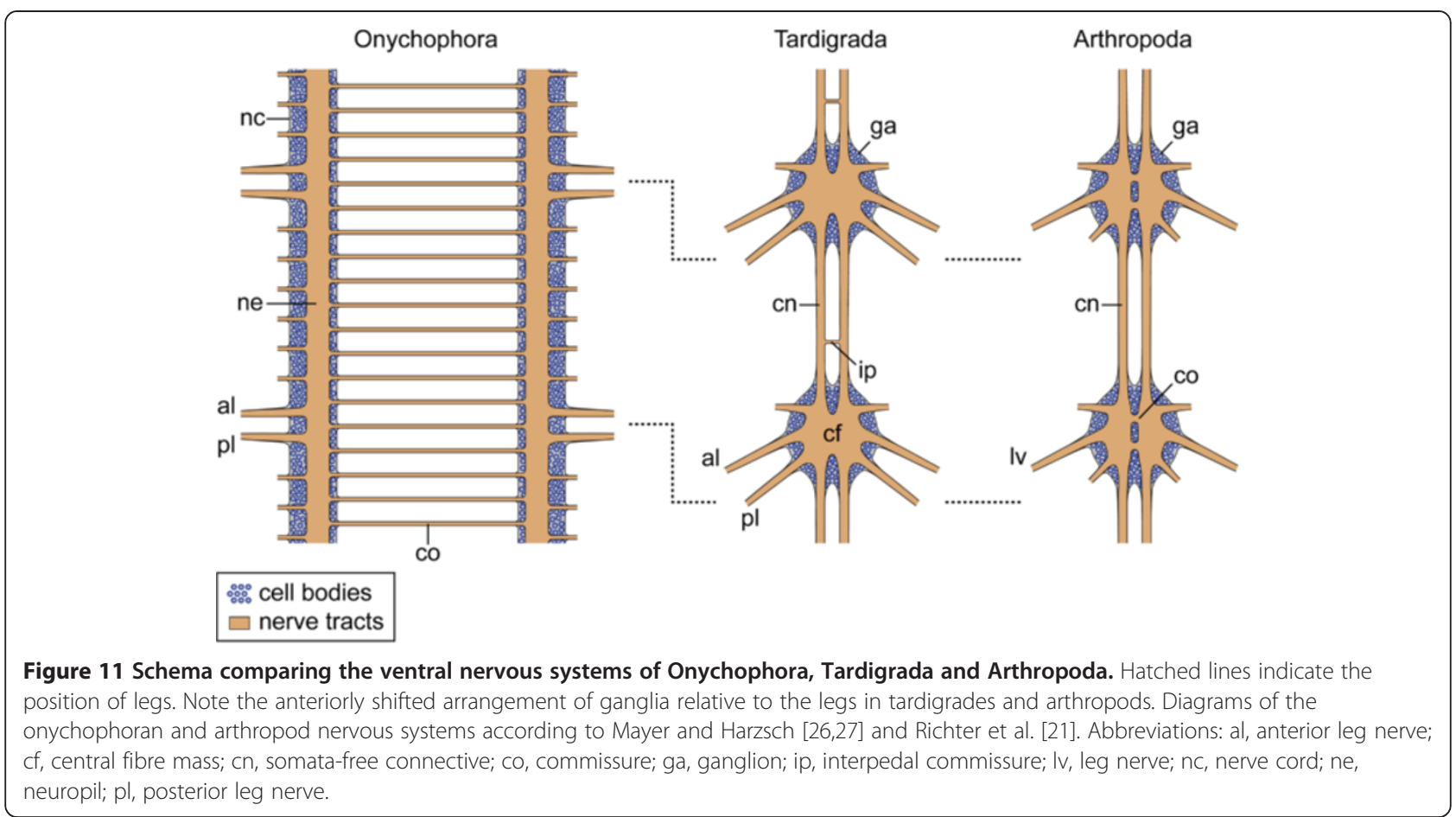

an epitope located on the $\alpha 3$ isoform of Chlamydomonas axonemal $\alpha$-tubulin, within four residues of Lys ${ }^{40}$ when this amino acid is acetylated [55].

In addition, we used four antisera that recognise different neuromodulators that are common in invertebrates: (1) Anti-serotonin (NT 102 Eugene Tech Inc., NJ, USA; currently Protos Biotech, NJ, USA; diluted 1:1000) is a polyclonal antiserum raised in rabbits against the biogenic amine serotonin, coupled to Limulus haemocyanin. Since we cannot fully exclude that the antiserum may bind to serotonin-related substances, in addition to serotonin, we refer to the observed labelling as "serotonin-like" immunoreactivity. (2) Anti-FMRFamide (Incstar, Stillwater, MN, USA; currently ImmunoStar, Hudson, WI, USA; diluted 1:1000) is a polyclonal antiserum raised in rabbits against the neuropeptide FMRFamide coupled to bovine thyroglobulin. We refer to the labelled structures in our specimens as "RFamide-like" immunoreactivity since the antibody labels a variety of peptides terminating with the sequence RFamide. (3) Anti-allatostatin, a polyclonal antiserum directed against the peptide allatostatin I (Dip-allatostatin I, APSGAQRLYGFGL-amide) from the cockroach Diploptera punctata, originated from the producer Dr Hans Agricola (Friedrich Schiller University, Jena, Germany). We used it at a dilution of 1:5000. This serum recognises allatostatins $\mathrm{I}-\mathrm{V}$, but is almost two orders of magnitude more sensitive to AST-1 than to the other ASTs [56]. The antiserum has been used in cockroaches and locusts [56]. We refer to the labelled structures in our specimens as "allatostatin-like" immunoreactivity. (4) Anti-perisulphakinin, an antiserum against pea-sulfakinin (perisulfakinin), originated from the producer Dr Hans Agricola (Friedrich Schiller University, Jena, Germany), who has used it successfully in various insects as well as in spiders, crustaceans, centipedes and annelids [57-59]. We used it at a dilution of 1:5000. Perisulfakinin belongs to a family of peptides with identical C-terminal sequences (sulphakinis) that share structural similarities with vertebrate cholecystokinin/gastrin peptide and invertebrate FMRFamide-like peptides $[57,58]$. We refer to the labelled structures in our specimens as "perisulfakinin-like" immunoreactivity.

All antibodies were diluted in $1 \%$ normal goat serum in 0.1 M PBS, pH 7.4, containing 1\% Triton-X100. Bound antisera were detected using Alexa 488- or 568-tagged secondary antibodies (Invitrogen, Carlsbad, CA, USA) diluted 1:500. After several rinses in PBS, some specimens were incubated for one hour in a solution containing phalloidin-rhodamine (Invitrogen) to stain $\mathrm{f}$-actin as described previously $[8,24,60]$. After additional rinses in PBS, the DNA-selective fluorescent dyes Hoechst (Bisbenzimide, H33258; Sigma-Aldrich; $1 \mu \mathrm{g} / \mathrm{ml}$ in PBS), SYBR $^{\circ}$ Green (Invitrogen; 1:10000 in PBS) or RedDot ${ }^{\mathrm{TM}} 2$ (Biotium, Hayward, CA, USA; 1:250 in PBS) were applied according to the manufacturers' protocols. Specimens were then rinsed in PBS and mounted between two cover slips in Vectashield mounting medium (Vector Laboratories Inc., Burlingame, CA, USA) or dehydrated in an ethanol series and mounted in methyl salicylate. 


\section{Retrograde staining of onychophoran motor nerves}

For neuronal tracing, the onychophoran nerve cords were dissected in physiological saline [61]. Retrograde fills of leg nerves and ring commissures were carried out with dextran coupled to tetramethylrhodamine as described previously $[62,63]$. Stained nerve cords were dehydrated through a methanol series and mounted between two cover slips in methyl salicylate.

\section{Transmission electron microscopy on tardigrades}

For ultrastructural studies, specimens of the tardigrade Macrobiotus cf. harmsworthi were prepared using standard methods as described previously [64] and embedded in Epoxy Embedding Medium Kit (Sigma, St. Louis, MO). Ultra-thin sections were cut on a Leica Ultracut UCT25 ultramicrotome (Leica Microsystems, Wetzlar, Germany), stained with uranyl acetate and lead citrate and examined using a Hitachi H500 transmission electron microscope (Hitachi Ltd, Tokyo, Japan) at $75 \mathrm{kV}$.

\section{Confocal microscopy, light microscopy and image processing} Specimens were analysed with the confocal laserscanning microscopes Zeiss LSM 510 META (Carl Zeiss MicroImaging GmbH, Jena, Germany) and Leica TCS STED (Leica Microsystems, Wetzlar, Germany). Confocal image stacks were processed with Zeiss LSM IMAGE BROWSER v4.0.0.241 (Carl Zeiss MicroImaging GmbH) and Leica AS AF v2.3.5 (Leica Microsystems). The overall structure of the onychophoran nervous system and the position of leg nerves were analysed with a stereomicroscope (Leica Wild M10) equipped with a colour digital camera (PCO AG SensiCam, Kelheim, Germany). The overall anatomy of tardigrades was analysed under a transmitted light microscope (Leica Leitz DMR; Leica Microsystems), equipped with a colour digital camera (PCO AG SensiCam). Several micrographs were taken from each specimen at different focal planes and merged to a single projection using the Auto-Blend Layers function in Adobe (San Jose, CA, USA) Photoshop CS4. Final panels and diagrams were produced using Adobe Illustrator CS4 and exported to Tagged Image File Format files.

\section{Animal ethics}

The experiments in this study did not require an approval by an ethical committee. All procedures in this investigation complied with international and institutional guidelines, including the guidelines for animal welfare as laid down by the German Research Foundation (DFG).

\section{Additional files}

Additional file 1: Organisation of the brain and the four trunk ganglia in two specimens of the tardigrade Macrobiotus cf.

harmsworthi. Anti-RFamide-like immunoreactivity. Confocal micrographs of brains in dorsal view and trunk ganglia in ventral view; anterior is up in all images. Note the similar organisation of the brain and trunk ganglia in the two specimens. Arrowheads point to the repeated somata of RFamide-like immunoreactive neurons within the second and third trunk ganglia. Abbreviations: cn, connective; ex, extra-cerebral neuronal cell body; ic, inner connective; $\mathrm{np}$, central brain neuropil; so, neuronal somata. Scale bars: $5 \mu \mathrm{m}$.

Additional file 2: Organisation of the ventral nervous system in the tardigrade Hypsibius dujardini. Note the extra-ganglionic, interpedal commissures in front of the second, third and fourth trunk ganglia (arrowheads). Combined anti-tyrosinated and anti-acetylated a-tubulin immunolabelling. Confocal micrographs; anterior is up. (A) Specimen in lateral view. (B) Specimen in ventral view. Abbreviations: al, anterior leg nerve; cn, connective; ga2-ga4, trunk ganglia 2 to 4; lg, leg ganglion; pl, posterior leg nerve; pn, peripheral nerve. Scale bars: $10 \mu \mathrm{m}$.

Additional file 3: Organisation of the ventral nervous system in the tardigrade Macrobiotus cf. harmsworthi. Anti-RFamide-like immunoreactivity; confocal micrographs; anterior is up in all images. Note the lack of signal in the interpedal commissures (asterisks). Arrowheads (in A and B) point to the repeated somata of RFamide-like immunoreactive neurons within the second and third trunk ganglia. (A) Detail of the first and second trunk ganglia. (B) Detail of the third trunk ganglion. (C) Detail of the fourth trunk ganglion. Abbreviations: cn, connective; ga1-ga4, trunk ganglia 1 to 4 . Scale bars: $5 \mu \mathrm{m}$.

Additional file 4: Organisation of the ventral nervous system in the tardigrade Macrobiotus cf. harmsworthi. RFamide-like

immunoreactivity (glow mode) and DNA labelling (light blue); confocal micrographs; anterior is up in all images. (A) Entire specimen in ventral view. Asterisks indicate the position of the interpedal commissures. (B-D) Details of the posterior end showing the position of two RFamide-like immunoreactive somata associated with cloacal nerves (arrows). Abbreviations: $\mathrm{Cl}$, cloacal nerve; cn, connectives; ga1-ga4, trunk ganglia 1 to 4; ic, inner connective; le1-le4, walking legs 1 to 4; pg, peripheral ganglion; pn, peripheral nerve. Scale bars: $20 \mu \mathrm{m}(\mathrm{A})$ and $10 \mu \mathrm{m}$ (B-D).

Additional file 5: Organisation of the ventral nervous system at the posterior end in the tardigrade Macrobiotus cf. harmsworthi. Serotonin-like immunoreactivity (glow mode) and DNA labelling (light blue); confocal micrographs. Arrowheads point to the somata of serotonin-like immunoreactive neurons. (A) Specimen in ventral view; anterior is up. Note the absence of signal in the interpedal commissure (asterisk). (B-D) Details of the posterior end showing the position of two platelet-shaped, serotonin-like immunoreactive structures (=putative release cites) associated with cloacal nerves (arrows). Abbreviations: cl, cloacal nerve; cn, connectives; ga3-ga4, trunk ganglia 3 to 4. Scale bars: $10 \mu \mathrm{m}$ (A-D).

Additional file 6: Anti-allatostatin immunolabelling in the tardigrade Hypsibius dujardini. Confocal micrographs; anterior is up in all images. Note the lack of signal in the interpedal commissures (asterisks; cf. Additional file 2). Arrowheads (in C) indicated the position of the two platelet-shaped structures associated with cloacal nerves. (A) Details of the brain in dorsal view. (B) Detail of the first and second trunk ganglia in ventral view. (C) Detail of the third and fourth trunk ganglia. Abbreviations: cn, connective; ga1-ga4, trunk ganglia 1 to 4 ; ic, inner connective; so, somata of allatostatin-like immunoreactive neurons. Scale bars: $10 \mu \mathrm{m}$.

\section{Competing interests}

The authors declare that they have no competing interests.

\section{Authors' contributions}

GM conceived and designed the experiments, analysed the data and wrote the first draft of the manuscript. CM, JR, SK and IP performed the experiments. CM, JR, SK, PAS, IP, KH, ROS, HJP and MS participated in data analysis and helped to draft the manuscript. All authors read, made comments on and approved the final manuscript.

\section{Acknowledgements}

We are thankful to Andreas Hejnol for providing details on the anti-tyrosinated a-tubulin antibody and to Noel Tait for his help with the collecting permits. The staff members of the State Forests NSW (New South Wales, Australia) are 
gratefully acknowledged for providing the collecting permits. This work was supported by a grant from the German Research Foundation (DFG; grant Ma 4147/3-1) to GM, who is a Research Group Leader supported by the Emmy Noether Programme of the DFG.

\section{Author details}

${ }^{1}$ Animal Evolution and Development, Institute of Biology, University of Leipzig, Talstraße 33, D-04103 Leipzig, Germany. ${ }^{2}$ Physiology of Animals and Behavior, Institute of Biology, University of Leipzig, Talstraße 33, D-04103 Leipzig, Germany. ${ }^{3}$ Department of Animal Histology and Embryology, University of Silesia, Bankowa 9, 40-007 Katowice, Poland. ${ }^{4}$ Senckenberg Museum of Natural History Görlitz, Am Museum 1, D-02826 Görlitz, Germany. ${ }^{5}$ Biological Institute, Zoology, University of Stuttgart, Pfaffenwaldring 57, D-70569 Stuttgart, Germany. ${ }^{6}$ Neurobiology, Institute of Biology, Freie Universität Berlin, Königin-Luise-Str. 28-30, D-14195 Berlin, Germany. ${ }^{7}$ Molecular Evolution \& Animal Systematics, Institute of Biology, University of Leipzig, Talstraße 33, D-04103 Leipzig, Germany. ${ }^{8}$ German Centre for Integrative Biodiversity Research (iDiv), Halle-Jena-Leipzig, Deutscher Platz 5e, D-04103 Leipzig, Germany.

\section{Received: 14 August 2013 Accepted: 16 October 2013}

Published: 24 October 2013

\section{References}

1. Budd GE: Tardigrades as 'stem-group arthropods': the evidence from the Cambrian fauna. Zool Anz 2001, 240:265-279.

2. Mallatt J, Giribet G: Further use of nearly complete $28 \mathrm{~S}$ and $18 \mathrm{~S}$ rRNA genes to classify Ecdysozoa: 37 more arthropods and a kinorhynch. Mol Biol Evol 2006, 40:772-794.

3. Roeding F, Hagner-Holler S, Ruhberg H, Ebersberger I, von Haeseler A, Kube M, Reinhardt R, Burmester T: EST sequencing of Onychophora and phylogenomic analysis of Metazoa. Mol Phylogenet Evol 2007, 45:942-951

4. Dunn CW, Hejnol A, Matus DQ, Pang K, Browne WE, Smith SA, Seaver E, Rouse GW, Obst M, Edgecombe GD, et al: Broad phylogenomic sampling improves resolution of the animal tree of life. Nature 2008, 452:745-749.

5. Lartillot N, Philippe $H$ : Improvement of molecular phylogenetic inference and the phylogeny of Bilateria. Philos Trans R Soc B Biol Sci 2008, 363:1463-1472.

6. Telford MJ, Bourlat SJ, Economou A, Papillon D, Rota-Stabelli O: The evolution of the Ecdysozoa. Philos Trans R Soc B Biol Sci 2008, 363:1529-1537.

7. Hejnol A, Obst M, Stamatakis A, Ott M, Rouse GW, Edgecombe GD, Martinez $P$, Baguñà J, Bailly $X$, Jondelius $U$, et al: Assessing the root of bilaterian animals with scalable phylogenomic methods. Proc R Soc B Biol Sci 2009, 276:4261-4270.

8. Mayer G, Whitington PM: Neural development in Onychophora (velvet worms) suggests a step-wise evolution of segmentation in the nervous system of Panarthropoda. Dev Biol 2009, 335:263-275.

9. Roeding F, Borner J, Kube M, Klages S, Reinhardt R, Burmester T: A 454 sequencing approach for large scale phylogenomic analysis of the common emperor scorpion (Pandinus imperator). Mol Phylogenet Evol 2009, 53:826-834.

10. Meusemann K, von Reumont BM, Simon S, Roeding F, Strauss S, Kück P, Ebersberger I, Walzl M, Pass G, Breuers S, et al: A phylogenomic approach to resolve the arthropod tree of life. Mol Biol Evol 2010, 27:2451-2464.

11. Rota-Stabelli O, Kayal E, Gleeson D, Daub J, Boore J, Telford M, Pisani D, Blaxter M, Lavrov D: Ecdysozoan mitogenomics: evidence for a common origin of the legged invertebrates, the Panarthropoda. Genome Biol Evol 2010, 2:425-440.

12. Campbell LI, Rota-Stabelli O, Edgecombe GD, Marchioroc T, Longhorna SJ, Telford MJ, Philippe H, Rebecchi L, Peterson KJ, Pisani D: MicroRNAs and phylogenomics resolve the relationships of Tardigrada and suggest that velvet worms are the sister group of Arthropoda. Proc Natl Acad Sci U S A 2011, 108:15920-15924.

13. Rehm P, Borner J, Meusemann K, von Reumont BM, Simon S, Hadrys H, Misof B, Burmester T: Dating the arthropod tree based on large-scale transcriptome data. Mol Phylogenet Evol 2011, 61:880-887.

14. Giribet $\mathrm{G}$, Edgecombe $\mathrm{G}$ : Reevaluating the arthropod tree of life. Annu Rev Entomol 2012, 57:167-186.

15. Nielsen C: Animal Evolution: Interrelationships of the Living Phyla. Oxford: Oxford University Press; 2012

16. Arango CP, Wheeler WC: Phylogeny of the sea spiders (Arthropoda, Pycnogonida) based on direct optimization of six loci and morphology. Cladistics 2007, 23:1-39.
17. Bergsten J: A review of long-branch attraction. Cladistics 2005, 21:163-193.

18. Wägele JW, Mayer C: Visualizing differences in phylogenetic information content of alignments and distinction of three classes of long-branch effects. BMC Evol Biol 2007, 7:147.

19. Kück P, Mayer C, Wägele J-W, Misof B: Long branch effects distort maximum likelihood phylogenies in simulations despite selection of the correct model. PLOS ONE 2012, 7(5):e36593.

20. Harzsch S: Neurophylogeny: architecture of the nervous system and a fresh view on arthropod phyologeny. Integr Comp Biol 2006, 46:162-194.

21. Richter S, Loesel R, Purschke G, Schmidt-Rhaesa A, Scholtz G, Stach T, Vogt $L$, Wanninger A, Brenneis $G$, Döring $C$, et al: Invertebrate neurophylogeny: suggested terms and definitions for a neuroanatomical glossary. Front Zool 2010, 7:29.

22. Marcus E: Tardigrada. In Dr H G Bronns Klassen und Ordnungen des Tier-Reichs wissenschaftlich dargestellt in Wort und Bild, Volume 5. Leipzig: Akademische Verlagsgesellschaft; 1929:1-609.

23. Persson DK, Halberg KA, Jørgensen A, Møbjerg N, Kristensen RM: Neuroanatomy of Halobiotus crispae (Eutardigrada: Hypsibiidae): tardigrade brain structure supports the clade Panarthropoda. J Morphol 2012, 273:1227-1245.

24. Mayer G, Kauschke S, Rüdiger J, Stevenson PA: Neural markers reveal a one-segmented head in tardigrades (water bears). PLOS ONE 2013, 8(3):e59090

25. Schulze C, Schmidt-Rhaesa A: The architecture of the nervous system of Echiniscus testudo (Echiniscoidea, Heterotardigrada). J Limnol 2013, 72:44-53.

26. Mayer G, Harzsch S: Immunolocalization of serotonin in Onychophora argues against segmental ganglia being an ancestral feature of arthropods. BMC Evol Biol 2007, 7:118.

27. Mayer G, Harzsch S: Distribution of serotonin in the trunk of Metaperipatus blainvillei (Onychophora, Peripatopsidae): implications for the evolution of the nervous system in Arthropoda. J Comp Neurol 2008, 507:1196-1208.

28. Whitington PM, Mayer $\mathrm{G}$ : The origins of the arthropod nervous system: insights from the Onychophora. Arthropod Struct Dev 2011, 40:193-209.

29. Doyère M: Mémoire sur les Tardigrades. Ann Sci Nat (Paris), Zoo 1840, 14(2):269-361.

30. Greeff R: Ueber das Nervensystem der Bärthierchen, Arctiscoida C.A.S. Schultze (Tardigraden Doyère) mit besonderer Berücksichtigung der Muskelnerven und deren Endigungen. Arch Mikrosk Anat 1865, 1:101-123.

31. Plate L: Beiträge zur Naturgeschichte der Tardigraden. Zool Jahrb Abt Anat Ontog Tiere 1889, 3:487-550.

32. Zantke J, Wolff C, Scholtz G: Three-dimensional reconstruction of the central nervous system of Macrobiotus hufelandi (Eutardigrada, Parachela): implications for the phylogenetic position of Tardigrada. Zoomorphology 2008, 127:21-36.

33. Edgecombe GD: Palaeontological and molecular evidence linking arthropods, onychophorans, and other Ecdysozoa. Evo Edu Outreach 2009, 2:178-190.

34. Greven H, Kuhlmann D: Die Struktur des Nervengewebes von Macrobiotus hufelandi C.A.S. Schultze (Tardigrada). Z Zellforsch 1972, 132:131-146

35. Harzsch S: Phylogenetic comparison of serotonin-immunoreactive neurons in representatives of the Chilopoda, Diplopoda, and Chelicerata: implications for arthropod relationships. J Morphol 2004, 259:198-213.

36. Kristensen RM, Higgins RP: A new family of Arthrotardigrada (Tardigrada: Heterotardigrada) from the Atlantic Coast of Florida. U S A Trans Am Microsc Soc 1984, 103:295-311.

37. Kristensen RM, Higgins RP: Revision of Styraconyx (Tardigrada: Halechiniscidae) with descriptions of two new species from Disko Bay, West Greenland. Smithson Contrib Zool 1984, 391:1-40.

38. Deutsch JS: Segments and parasegments in arthropods: a functional perspective. BioEssays 2004, 26:1117-1125.

39. Damen WGM: Evolutionary conservation and divergence of the segmentation process in arthropods. Dev Dyn 2007, 236:1379-1391.

40. Gabriel WN, Goldstein B: Segmental expression of Pax3/7 and Engrailed homologs in tardigrade development. Dev Genes Evol 2007, 217:421-433.

41. Eriksson BJ, Tait NN, Budd GE, Akam M: The involvement of engrailed and wingless during segmentation in the onychophoran Euperipatoides kanangrensis (Peripatopsidae: Onychophora) (Reid 1996). Dev Genes Evol 2009, 219:249-264

42. Bullock TH: Annelida. In Structure and Function in the Nervous Systems of Invertebrates, Volume I. Edited by Bullock TH, Horridge GA. San Francisco, California: W.H. Freeman Company; 1965:661-789.

43. Bullock TH: Pseudocoelomate phyla: Acanthocephala, Rotifera, Gastrotricha, Kinorhyncha, Nematoda, Nematomorpha, and Entoprocta. 
In Structure and Function in the Nervous Systems of Invertebrates, Volume I. Edited by Bullock TH, Horridge GA. San Francisco, California: W.H. Freeman Company; 1965:597-629.

44. Kristensen RM, Higgins RP: Kinorhyncha. In Microscopic Anatomy of Invertebrates. Volume 4. Aschelminthes. Edited by Harrison FW, Ruppert EE. New York: Wiley-Liss; 1991:377-404.

45. Nebelsick M: Introvert, mouth cone, and nervous system of Echinoderes capitatus (Kinorhyncha, Cyclorhagida) and implications for the phylogenetic relationships of Kinorhyncha. Zoomorphology 1993, 113:211-232.

46. Scholtz G: The Articulata hypothesis - or what is a segment? Org Divers Evol 2002, 2:197-215

47. Orrhage L, Müller MCM: Morphology of the nervous system of Polychaeta (Annelida). Hydrobiologia 2005, 535/536:79-111.

48. Hoyle G, Williams M: The musculature of Peripatus and its innervation. Philos Trans R Soc B Biol Sci 1980, 288:481-510

49. Müller MCM, Schmidt-Rhaesa A: Reconstruction of the muscle system in Antygomonas sp. (Kinorhyncha, Cyclorhagida) by means of phalloidin labeling and CLSM. J Morphol 2003, 256:103-110.

50. Rothe BH, Schmidt-Rhaesa A: Probable development from continuous to segmental longitudinal musculature in Pycnophyes kielensis (Kinorhyncha, Homalorhagida). Meiofauna Mar 2004, 13:21-28.

51. Schmidt-Rhaesa A, Rothe H: Postembryonic development of dorsoventral and longitudinal musculature in Pycnophyes kielensis (Kinorhyncha, Homalorhagida). Integr Comp Biol 2006, 46:144-150.

52. Hohberg K: Tardigrade species composition in young soils and some aspects on life history of Macrobiotus richtersi J. Murray, 1911. Pedobiologia 2006, 50:267-274.

53. Kreis TE: Microtubules containing detyrosinated tubulin are less dynamic. EMBO J 1987, 6:2597-2606.

54. Siddiqui SS, Aamodt E, Rastinejad F, Culotti J: Anti-tubulin monoclonal antibodies that bind to specific neurons in Caenorhabditis elegans. J Neurosci 1989, 9:2963-2972.

55. LeDizet M, Piperno G: Identification of an acetylation site of Chlamydomonas a-tubulin. Proc Natl Acad Sci U S A 1987, 84:5720-5724.

56. Vitzthum $\mathrm{H}, \mathrm{Homberg} U$, Agricola H: Distribution of Dip-allatostatin I-like Immunoreactivity in the brain of the locust Schistocerca gregaria with detailed analysis of immunostaining in the central complex. J Comp Neurol 1996, 369:419-437.

57. Agricola HJ, Bräunig P: Comparative aspects of peptidergic signaling pathways in the nervous systems of arthropods. In The Nervous Systems of Invertebrates: An Evolutionary and Comparative Approach. Edited by Breidbach O, Kutsch W. Basel: Birkhäuser Verlag; 1995:303-327.

58. Utting M, Agricola H-J, Sandeman R, Sandeman D: Central complex in the brain of crayfish and its possible homology with that of insects. J Comp Neurol 2000, 416:245-261.

59. Loesel R, Seyfarth E-A, Bräunig P, Agricola H-J: Neuroarchitecture of the arcuate body in the brain of the spider Cupiennius salei (Araneae, Chelicerata) revealed by allatostatin-, proctolin-, and CCAP-immunocytochemistry and its evolutionary implications. Arthropod Struct Dev 2011, 40:210-220.

60. Mayer $G$, Whitington PM: Velvet worm development links myriapods with chelicerates. Proc R Soc B Biol Sci 2009, 276:3571-3579.

61. Robson EA, Lockwood APM, Ralph R: Composition of the blood in Onychophora. Nature 1966, 209:533.

62. Mayer $G$, Whitington $P M$, Sunnucks $P$, Pflüger $H$-J: A revision of brain composition in Onychophora (velvet worms) suggests that the tritocerebrum evolved in arthropods. BMC Evol Biol 2010, 10:255.

63. Pflüger HJ, Field LH: A locust chordotonal organ coding for proprioceptive and acoustic stimuli. J Comp Physiol A 1999, 184:169-183.

64. Poprawa I: Ultrastructural studies of the formation of the egg capsule in the hermaphroditic species, Isohypsibius granulifer granulifer Thulin, 1928 (Eutardigrada: Hypsibiidae). Zool Sci 2011, 28:37-40.

doi:10.1186/1471-2148-13-230

Cite this article as: Mayer et al.: Selective neuronal staining in tardigrades and onychophorans provides insights into the evolution of segmental ganglia in panarthropods. BMC Evolutionary Biology 2013 13:230.

\section{Submit your next manuscript to BioMed Central and take full advantage of:}

- Convenient online submission

- Thorough peer review

- No space constraints or color figure charges

- Immediate publication on acceptance

- Inclusion in PubMed, CAS, Scopus and Google Scholar

- Research which is freely available for redistribution

Submit your manuscript at www.biomedcentral.com/submit
C Biomed Central 